Aim of the study: Thermoablation of metastatic lesions in the liver is very commonplace. At present there are 3 essential techniques of access to carry out the procedure: open surgery, percutaneous technique and laparoscopic method. Percutaneous thermoablation is criticised due to the possible lack of radicalism. On the other hand, thermoablation during open surgery is a big perioperative trauma for the patient. The laparoscopic technique seems to be a compromise between the aforementioned techniques. The aim of this study was to present the technique and preliminary results of thermoablation of the liver carried out by means of the laparoscopic technique.

Material and methods: Laparoscopic thermoablation was carried out in 4 patients with colorectal cancer metastases to the liver. In order to precisely locate the tumour and guarantee radicalism of the surgery, laparoscopic probe ultrasonography was carried out during the procedure.

Results: All the patients underwent the procedure without any difficulties. All the patients left the hospital department as soon as 3 or 4 days after the surgery. This was about 7 days earlier in comparison with the open surgery procedure, which had been carried out before. The patients required a supply of analgesics only during the first 48 hours - non-steroid anti-inflammatory drugs, which made a substantial difference between them and the patients treated with the open surgical technique. Thanks to the laparoscopic ultrasound technique one patient had an additional lesion located, which had not been described in preoperative examinations.

Conclusions: In combination with ultrasonography, laparoscopic access, which does not have a very invasive character, seems to be relatively simple and effective to carry out the procedure of thermoablation.

Key words: laparoscopy, thermoablation, liver metastases.

\section{Laparoscopic thermoablation of colorectal cancer metastases to the liver - new experience of the centre}

Dawid Murawa ${ }^{1}$, Arkadiusz Spychała ${ }^{1}$, Adam Lewandowski ${ }^{2}$, Piotr Nowaczyk ${ }^{1}$

1First Department of Surgical Oncology, Greater Poland Cancer Center, Poznań, Poland 2Department of Radiology, Greater Poland Cancer Center, Poznań, Poland

\section{Introduction}

Colorectal cancer is the most frequent malignant cancer of the alimentary tract. In spite of early detection programmes there are still about $15-20 \%$ of patients who report for treatment at stage IV of the neoplastic disease. In a group of patients with the diagnosis of colorectal cancer as many as $40-50 \%$ of them develop metastases within the liver during the natural process of disease progression [1-3]. The treatment of patients with colorectal cancer metastases to the liver is a multidisciplinary procedure, where one of the elements is surgical destruction or resection. Surgical resection of a lesion in the liver is a voluntary procedure in patients with surgical metastasis of colorectal cancer, which gives a chance for recovery. However, only $10-20 \%$ of patients may be qualified for potentially therapeutic resection due to the number of lesions, their size, location in the hepatic parenchyma, chronic liver disease as well as concomitant diseases [2, 3]. If no treatment is applied, the average survival time for patients with metastases in the liver is about 5-6 months, where the cause of death is usually failure of the organ [1]. An alternative to resection of the liver, especially in the situations discussed above, is the application of methods of thermal destruction of metastases (radiofrequency ablation - RFA) with simultaneous conservation of the remaining healthy hepatic parenchyma. The methods enable better results of treatment applied to patients. In the case of RFA the tissue is destroyed through the application of temperature reaching $90-100^{\circ} \mathrm{C}$. Protein denaturation and coagulative necrosis are the effects. Thermoablation can also be carried out with the application of different accesses. They range from the access during laparotomy, which is the most intrusive for the patient, through the application of laparoscopy in order to carry out percutaneous thermoablation controlled by ultrasound, computed tomography or magnetic resonance [4-8]. For the time being there is still a lot of controversy concerning the application of thermoablation techniques in the treatment of metastases to the liver. The vast majority of the available literature consists of retrospective studies, usually from one centre, which indicate that thermoablation produces worse results than surgical resection [9]. RFA supporters point to the fact that worse results are the effect of specific qualification of patients, i.e. those who cannot be qualified for resection due to progression of the disease or their general state [9].

Percutaneous thermoablation is criticised due to the possible lack of radicalism. On the other hand, thermoablation during open surgery means strong perioperative trauma for the patient. The laparoscopic technique enables minimisation of the surgery and the simultaneous possibility of direct visualisation of the liver, and intraoperative ultrasonography with the application of the laparoscopic head enables better visualisation not only of the liver but also of the entire peritoneal space $[10,11]$. 
Table 1. Characteristics of patients and the hepatic focal lesions treated with RFA

\begin{tabular}{|c|c|c|c|c|c|}
\hline & Age & Primary tumor & Staging & Adjuwant treatment & $\begin{array}{l}\text { Localisation and the size } \\
\text { of tumor in liver parenchyma (CT) }\end{array}$ \\
\hline 1 & 50 & Sigmo-rectal & T3 N2 G2 & FOLFOX $4 \times 6$ & Seg. $6-18 \times 12 \mathrm{~mm}$ \\
\hline 2 & 53 & Sigmoid colon & T3 N1 G3 & FOLFOX $4 \times 14$ & Seg. 5 - 11 mm; Seg. $8-12$ mm \\
\hline 3 & 54 & Sigmo-rectal & T3 N2 G2 & FOLFOX $4 \times 12$ & $\begin{array}{c}\text { Seg. } 4-28 \times 21 ; \text { Seg. } 6-23 \times 14 ; \\
\text { Seg. } 5 / 6-18 \mathrm{~mm}\end{array}$ \\
\hline 4 & 59 & Descending colon & T2N1G1 & FOLFOX4 × 12 & Seg $4 b / 3-29 \times 28 \mathrm{~mm}$ \\
\hline
\end{tabular}

The aim of the study was to present our first experiences in the technique, evaluation of its efficacy and limitations to thermoablation of colorectal cancer metastases to the liver carried out by means of the laparoscopic technique.

\section{Material and methods}

The group of examinees consisted of four patients with the diagnosis of colorectal cancer. In the last 6 months they had been treated in the $1^{\text {st }}$ Department of Surgical Oncology and General Surgery, Greaterpoland Cancer Center. The diagnostics revealed synchronic metastases within the liver. In the beginning the patients were qualified for resection of the primary lesion and later, after the final result of histopathological examination, neoadjuvant therapy was included. According to the recommendations of the clinical oncologist, the treatment involved computed tomography of the abdominal cavity in order to assess the lesions within the liver. The patients whose lesions were reduced during chemotherapy, did not exceed $3 \mathrm{~cm}$ in diameter and were located peripherally were qualified for laparoscopic thermoablation. Table 1 shows the characteristics of the research group.

Three trocars $(1 \times 5 \mathrm{~mm}, 2 \times 12 \mathrm{~mm})$ were entered in general anaesthesia after the development of pneumoperitoneum to the level of $12 \mathrm{~mm} \mathrm{Hg}$. Two patients had another trocar installed due to the need of better visualisation of the operated place in the liver (Fig. 1). After accessing the liver the entire abdominal cavity was assessed in order to exclude

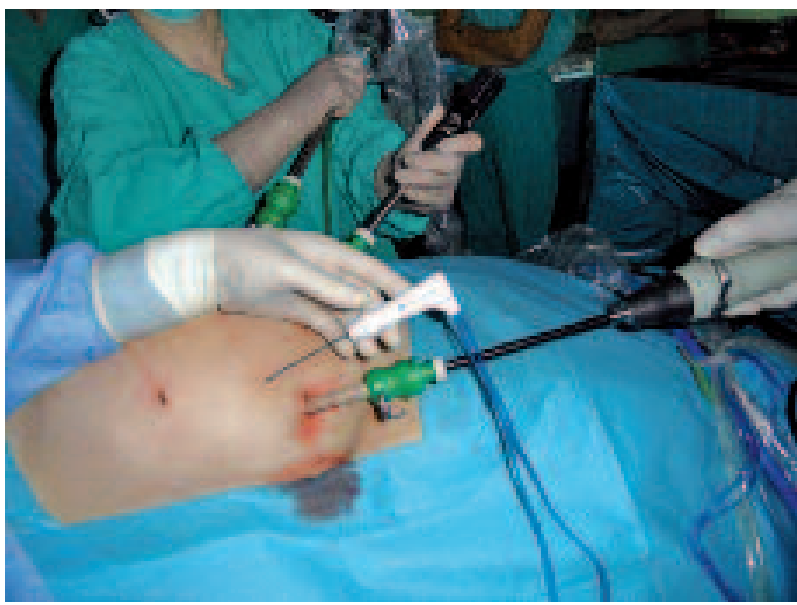

Fig. 1. Operating room setting and intraoperative field during laparoscopic RFA procedure spreading of the neoplastic process. Then the metastatic lesions described in computed tomography were located by means of a laparoscopic ultrasound head (ultrasound apparatus from BK-Medical, Herlev, Denmark and 8666-RF laparoscopic transducer) (Fig. 2). A thermoablation needle was entered percutaneously (needle $25 \mathrm{~cm}$, appliance Cool-tip RF ablation system, Valleylab, Tyco Healthcare group, USA). Then the needle was centrally entered into the lesion under the guidance of an ultrasound probe through its working channel or in the case of superficially located lesions the position of the needle was guided by ultrasound without using the working channel of the probe. Then the process of thermoablation was carried out, which lasted 12 minutes for one puncture (Fig. 3).

\section{Results}

In all of the four patients the procedure was carried out without any difficulties and the described lesions were located within the liver. In three of the patients all the lesions underwent thermoablation from a single puncture. It turned out that in patient no. 4, who had a single tumour in segment 4b, the lesion was larger than the one described in CT. Its diameter was $45 \mathrm{~mm}$ and it comprised the falciform ligament of the liver on one side and the wall of the gallbladder on the other side. First the patient underwent laparoscopic resections of a fragment of the falciform ligament and gallbladder. Thermoablation of the lesion was carried out from three separate punctures. Patient no. 1 had another lesion

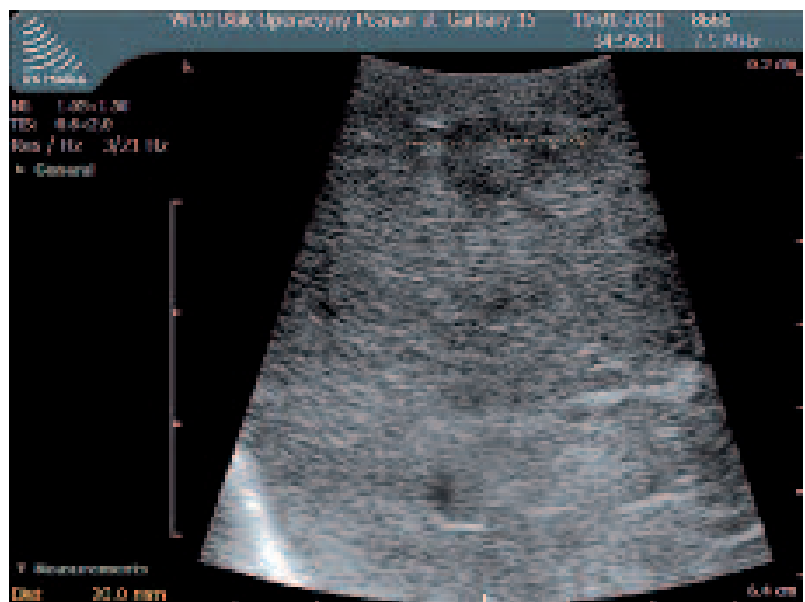

Fig. 2. Laparoscopic ultrasonography demonstrating a solitary metastatic carcinoma 
of $16 \mathrm{~mm}$ in diameter diagnosed in segment $\mathrm{V}$ by means of the ultrasound probe. Before thermoablation one of the patients had peritoneal adhesions of the hepatic region removed after open cholecystectomy.

The average operation time was 2 hours 20 minutes. In three patients the surgery did not last longer than 2 hours. The surgery on patient no. 2 lasted longer than 3 hours, which was caused by problems with appropriate visualisation and the actual process of thermoablation of the lesion located in segment VIII. All the patients had Redon drains removed within 24 hours after the surgery. The average amount of the drained substance was $50 \mathrm{ml}$. All the patients were discharged from the hospital department as early as the third or fourth day after the surgery. This was about 5 days earlier than in the case of open surgery, which was carried out before. The patients required a supply of analgesics only during the first 48 hours. They received non-steroid anti-inflammatory drugs, which made a substantial difference between them and patients treated by means of open surgery. During the perioperative course the patients underwent assessment of the marker CEA (carcinoembrionic antigen), which dropped to the normal level in all the patients. They also had a follow-up ultrasound of the abdominal cavity, which confirmed efficacy of the surgery. For further treatment the patients were qualified for continuation of chemotherapy or observation.

\section{Discussion}

Appropriate qualification for thermoablation continues to raise controversy. At the moment there are no prospective randomised clinical studies comparing the results of surgical treatment of colorectal cancer metastases by means of resection and thermoablation. Hamill et al. made a retrospective analysis of the results of treatment of potentially respective metastatic lesions of colorectal cancer to the liver by means of laparoscopic thermoablation. After another analysis of computed tomography images, from the patients who underwent laparoscopic thermoablation, a group of subjects who may have had a resection was selected. The results of treatment in the potentially resective group were as follows: the average survival time of 4.25 years and 5 -year survival time of $48.7 \%$ whereas in the non-resective group the average survival time was 2.16 years and 5 -year survival reached $18.4 \%$. The survival time in the group of potentially resective patients who had laparoscopic thermoablation was comparable with the results achieved after resection of the liver (from 33\% to 58\% as described in the literature) [10]. Oshowo et al. presented similar results, where the 3-year survival time of patients after resection of the liver was $55.4 \%$ as compared with $52.6 \%$ after thermoablation. The authors stress the need of further research which will unequivocally define indications for potentially therapeutic thermoablation with comparable results to resection [12].

The literature on thermoablation of metastatic lesions of colorectal cancer in the liver by the American Society of Clinical Oncology (ASCO) comprises 245 full-text publications in the Medline database. An overview of it shows that no prospective randomised studies have been published on the subject. The available studies, both prospective and retro-

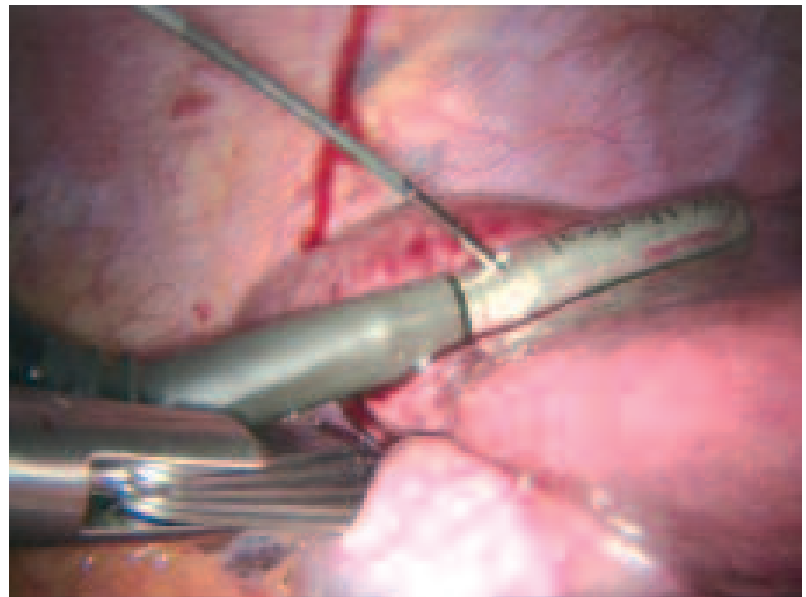

Fig. 3. Radiofrequency needle ablation through laparoscopic ultrasound

spective, point to considerable discrepancy between obtained results: 5 -year survival times between $14 \%$ and $55 \%$ and relapse after RFA between $3.6 \%$ and $60 \%$. Above all, such considerable differences are related to the criteria of qualification of patients and experience in the procedure. The best therapeutic results are obtained when patients with one metastatic lesion are qualified. Worse or good results are obtained if there are no more than three lesions. Bad results are achieved in the case of more than three lesions. Only one report in world literature points to the fact that RFA may extend the patient's total survival time if there are more than five lesions [9]. Similarly, the biggest success in RFA concerns the group of patients where the diameter of the metastatic lesion in the liver does not exceed $3 \mathrm{~cm}$. Most RFA apparatuses comprise the area of $4 \mathrm{~cm}$. In the case of lesions whose diameter does not exceed $3 \mathrm{~cm}$ this guarantees a 510- $\mathrm{mm}$ margin of healthy parenchyma in the liver. If thermoablation is applied as an alternative to resection, special attention should be paid to appropriate qualification of patients with smaller lesions than $3 \mathrm{~cm}$, located at the distance of at least $1 \mathrm{~cm}$ from the main bile ducts. Impairment of the main bile ducts entails a fatal complication, which narrows them down and leads to resulting consequences [5, 6, 9]. Patients in our centre were qualified for laparoscopic thermoablation on the basis of the aforementioned criteria.

The most important stage during thermoablation is appropriate visualisation of the lesion and precise entering of the electrode. The success and efficacy of the surgery depend on it. In order to visualise the lesion and carry out RFA the hepatic parenchyma can be accessed during the surgery - laparotomy or laparoscopy. Nevertheless, the least invasive method is percutaneous entering of needles under the control of ultrasonography, computed tomography or magnetic resonance. This technique is reserved for patients who cannot be qualified for general anaesthesia and/or who have numerous lesions, which are not large. The main disadvantages of percutaneous access are difficulty in precise location of lesions and absence of possibility to monitor the whole process.

In a comparison of the results of treatment and costs of hospitalisation of the patients who underwent percutaneous 
thermoablation guided by computed tomography and laparoscopy, it was observed that laparoscopy is the preferable access in patients with colorectal cancer metastases to the liver. In the group of patients with colorectal cancer metastases who underwent computed tomography-controlled thermoablation, in a month after the surgery the follow-up CT revealed absence of radicalism in a group of $12.5 \%$ of the patients. On the other hand, in the group who underwent surgery with the laparoscopic technique, radicalism was confirmed in all of the patients [11]. Furthermore, laparoscopy and laparotomy enable assessment of the whole abdominal cavity for spread of the neoplastic process in the peritoneum and location of metastases in other places. In our opinion laparoscopy is a good alternative to the intrusive laparotomy and it gives a possibility to achieve much better results than in the percutaneous access. As Thaler et al. suggest, before a decision of surgical treatment of colorectal cancer metastases to the liver, each patient should first undergo diagnostic laparoscopy with laparoscopic ultrasonography. In the analysis of 136 patients the application of laparoscopy changed the therapeutic decision during the surgery in $48 \%$. Simultaneously, after initial assessment in 78 cases laparoscopic thermoablation of metastatic lesions was carried out, whereas 26 patients underwent resection of the liver - 13 with laparoscopy and the other 13 from classical access [13]. It is important that patients with colorectal cancer metastases to the liver have appropriate diagnostics because it turns out that during laparotomy with intraoperative ultrasound assessment in 30\% of cases there are metastases identified in the liver, which were not earlier visible in imaging examinations $[14,15]$. In the presented material the whole abdominal cavity was assessed during the surgery, which enabled exclusion of the presence of neoplastic disease outside the hepatic tissue. In the presented group in one patient the laparoscopic ultrasound probe revealed an additional lesion, which had not been described before the surgery. It was also subjected to thermoablation.

Laparoscopic thermoablation of lesions in the liver has some limitations and the technique cannot be applied to all patients [6, 8, 16-18]. The first limitation described in the literature is the presence of massive adhesions within the abdominal cavity, which make access to the liver difficult. The vast majority of patients qualified for laparoscopic thermoablation have undergone resection of the colon or rectal cancer before. Some of those patients have been operated on due to metastases to the liver. Both of the operations are responsible for the development of adhesions. Releasing adhesions in order to gain free access to the liver carries higher risk of causing damage to other organs of the abdominal cavity, especially the intestine, and extends the surgery time [17]. In the presented material, when trocars were placed, adhesions were observed only after open resection of the gallbladder. They did not cause a serious problem and were resected by means of the laparoscopic technique. However, there were massive adhesions in the location after the colorectal surgery. In our group all the patients had cancer in the left half of the colorectum. The second limitation to the application of laparoscopic thermoablation is the number and location of lesions. In the case of larger tumours and difficult locations thermoablation during laparotomy provides more accurate and safer access. However, it depends on the surgeon's subjective opinion. At the moment there are no unequivocal guidelines which would specify the group of patients who would benefit more from thermoablation during laparotomy rather than laparoscopy [5, 6, 8, 16-18]. As Kulaylat suggests, smaller lesions of $1-3 \mathrm{~cm}$ in diameter, which are located superficially or peripherally, should be qualified for laparoscopic thermoablation. In the case of larger lesions or those located deep in the hepatic parenchyma, thermoablation from access during laparotomy seems to be better [4]. In an overview of the literature on thermoablation the ASCO reports the fact that one of the problems that needs to be explained by means of randomised clinical studies is the definition of appropriate qualification for a specific technique of thermoablation: percutaneous, laparoscopic or during laparotomy [9].

In our opinion, in the case of patients with colorectal cancer metastases to the liver, the presented technique is a good alternative to thermoablation carried out with the open method. It is important that patients are appropriately qualified for the laparoscopic procedure and it is necessary to have experience in this type of surgery. On the basis of experience in the open method of the procedure and the example of the patients we have presented above, we think that the laparoscopic technique is a safe and relatively simple procedure for a surgeon who applies laparoscopic techniques. In comparison with open surgery the noticeable elements are much shorter time of hospitalisation and recovery to physical activity. It is necessary to carry out many more operations in order to specify significant limitations to these techniques.

\section{References}

1. Fong Y, Cohen AM, Fortner JG, Enker WE, Turnbull AD, Coit DG, Marrero AM, Prasad M, Blumgart LH, Brennan MF. Liver resection for colorectal metastases. J Clin Oncol 1997; 15: 938-46.

2. Scheele J, Stangl R, Altendorf-Hoffman A. Staging of resectable colorectal liver metastases. Surgery 1996; 119: 118-20.

3. Petrelli NJ, Abbruzzese J, Mansfield P, Minsky B. Hepatic resection: the last surgical frontier for colorectal cancer. J Clin Oncol 2005; 23 : 4475-7.

4. Kulaylat M, Gibbs JF. Thermoablation of colorectal liver metastasis. J Surg Oncol 2010; 101: 699-705.

5. Kunzli BM, Abitabile P, Maurer ChA. Radiofrequency ablation of liver tumors: actual limitations and potential solutions in the future. World J Hepatol 2011; 3: 8-14.

6. Kuvshinott BW, Ota DM. Radiofrequency ablation of liver tumors: Influence of technique and tumor size. Surgery 2002; 132: 605-11.

7. Rocha FG, D'Angelica M. Treatment of liver colorectal metastases: role of laparoscopy, radiofrequency ablation and microwave coagulation. J Surg Oncol 2010; 102: 968-74.

8. Machi J, Uchida S, Sumida K, Limm WM, Hundachi SA, Oishi AJ, Furumoto NL, Oishi RH. Ultrasound-guided radiofrequency thermal ablation of liver tumors: Percutaneous, laparoscopic and open surgical approaches. J Gastrointes Surg 2001; 5: 477-89.

9. Wong SL, Mangu PB, Choti MA, et al. American Society of Clinical Oncology 2009 clinical evidence review on radiofrequency ablation of hepatic metastases from colorectal cancer. J Clin Oncol 2010; 28: 493-508.

10. Hammill CW, Billingsley KG, Cassera MA, Wolf RF, Ujiki MB, Hansen PD. Outcome after laparoscopic radiofrequency ablation of technically resectable colorectal liver metastases. Ann Surg Oncol 2011; 18 : 1947-54.

11. Cassera MA, Potter KW, Ujiki MB, Swanstrom LL, Hansen PD. Computed tomography (CT)-guided versus lapatoscopic radiofrequency 
ablation: a single-institution comparison of morbidity rates and hospital costs. Surg Endosc 2011; 25: 1088-95.

12. Oshowo A, Gillams A, Harrison E, Lees WR, Taylor I. Comparison of resection and radiofrequency ablation for treatment of solitary colorectal liver metastases. Br I Surg 2003; 90: 1240-3.

13. Thaler K, Kanneganti S, Khajanchee Y, Wilson C, Swanstrom L, Hansen PD. The evolving role of staging laparoscopy in the treatment of colorectal hepatic metastasis. Arch Surg 2005; 140: 727-34.

14. Abdalla EK, Vauthey JN, Ellis LM, Ellis V, Pollock R, Broglio KR, Hess $K$, Curley SA. Recurrence and outcomes following hepatic resection, radiofrequency ablation, and combined resection/ablation for colorectal liver metastases. Ann Surg 2004; 239: 818-25.

15. Kornprat P, Jarnagin WR, DeMatteo RP, Fong Y, Blumgart LH, D'Angelica $M$. Role of intraoperative thermoablation combined with resection in the treatment of hepatic metastasis from colorectal cancer. Arch Surg 2007; 142: 1087-92.

16. Salama IA, Korayem E, Elabd O, El-Rafaie A. Laparoscopic ultrasound with radiofrequency ablation of hepatic tumors in cirrhotic patients. J Laparoendosc Adv Surg Tech A 2010; 20: 39-46.

17. Siperstein A, Garland A, Engle K, Rogers S, Berber E, String A, Foroutuni A, Ryan T. Laparoscopic radiofrequency ablation of primary and metastatic tumors: Technical consideration. Surg Endosc 2000; 14: 400-5.

18. Siperstein A, Garland A, Engle K, Rogers S, Berber E, Foroutani A, String A, Ryan T, Ituarte P. Local recurrence after laparoscopic radiofrequency thermal ablation of hepatic tumors. Ann Surg Oncol 2000; 7: 106-13.

\section{Address for correspondence}

\section{Dawid Murawa MD, PhD}

First Department of Surgical Oncology

Greater Poland Cancer Centre

Garbary 15

61-866 Poznań, Poland

e-mail:dmurawa@op.pl

Submitted: $\quad 16.08 .2011$

Accepted: $\quad$ 4.11.2011 